Because thoracic outlet vascular trauma is life-threatening owing to both exsanguination and late complications (e.g., thrombosis and aneurysms), surgical repair should be done as soon as possible with vascular anastomosis or venous or prosthetic grafts, depending on the location and type of injury. ${ }^{6}$ In some cases full or partial cardiopulmonary bypass may even be needed.

The overall survival of these patients depends on a prompt diagnosis and an aggressive surgical approach, the result of an initial awareness of the possibility of severe undiagnosed associated injuries of other intrathoracic structures. Therefore, in those cases in which unexplained hemodynamic or respiratory impairment develops after blunt chest trauma, combined thoracic vascular injuries must be suspected.

\section{REFERENCES}

1. Binet JP, Langlois J, Cormier JM, et al. A case of recent traumatic avulsion of the innominate artery at its origin from the aortic arch. J ThORAC CARDIOVASC SURG 1962;43:670-6.

2. Galbraith NF, Urschel HC, Wood RE, et al. Fracture of first rib associated with laceration of subclavian artery: report of a case and review of the literature. $\mathbf{J}$ Thorac Cardiovasc Surg 1973;65:649-52.

3. Poole GV. Fracture of the upper ribs and injury to the great vessels. Surg Gynecol Obstet 1989;169:27582 .

4. Meyer JP, Goldfaden D, Barret J, et al. Subclavian and innominate artery trauma: a recent experience with nine patients. J Cardiovasc Surg 1988;29:283-9.

5. George SM, Croce MA, Fabian TC, et al. Cervicothoracic arterial injuries: recommendations for diagnosis and management. World J Surg 1991;15:134-40.

6. McLean TR, McManus RP. Penetrating trauma involving the innominate artery. Ann Thorac Surg 1991;51: 113-5.

\title{
MODIFIED HEMI-FONTAN OPERATION AND SUBSEQUENT NONSURGICAL FONTAN COMPLETION
}

\author{
W. Konertz, MD, ${ }^{a}$ M. Schneider, MD, ${ }^{\mathrm{b}}$ V. Herwig, MD, ${ }^{\mathrm{a}}$ C. Kampmann, MD, ${ }^{\mathrm{b}}$ F. Waldenberger, MD, ${ }^{\mathrm{a}}$ and \\ G. Hausdorf, MD, ${ }^{\mathrm{b}}$ Berlin, Germany
}

Refinements in the management of patients with functional single ventricle led to the application of the Fontan principle (partial or total cavopulmonary connection) in patients whose condition is considered "nonideal" by standard criteria. ${ }^{1}$ Apart from the fenestrated Fontan operation, these include the so-called hemi-Fontan operation, the bidirectional Glenn shunt with subsequent Fontan operation, or, very recently, completion through an extracardiac conduit. ${ }^{2-4}$ All these staged procedures involve at least two operations. At the Charitè, HumboldtUniversity Berlin, we developed a procedure for a functional bidirectional Glenn operation (hemi-Fontan) with preparation for a later Fontan procedure that requires only catheter intervention to complete the Fontan repair.

Technique. The operation is performed by creating a total cavopulmonary connection with subtotal banding of the cardiac end of the superior vena cava (SVC) and incorporation of a multifenestrated lateral baffle, as in the

From the Departments of Cardiac Surgery ${ }^{a}$ and Paediatric Cardiology, ${ }^{b}$ Charitè, Humboldt-University Berlin, Berlin, Germany.

J Thorac CARdiovasc Surg 1995;110:865-7

Copyright $\mathbb{C} 1995$ by Mosby-Year Book, Inc.

$0022-5223 / 95 \$ 5.00+0 \quad \mathbf{1 2 / 5 4 / 6 3 0 6 4}$
Fontan procedure. The multifenestrated baffle can be placed during a short period of cardioplegic arrest. The baffle is constructed from a polytetrafluoroethylene prosthesis. According to the weight of the patient, five to seven $5 \mathrm{~mm}$ holes are punched in the baffle. After closure of the atrium, the aortic crossclamp is removed and the cavopulmonary connection is performed with the heart beating. The SVC is banded just above the cavoatrial junction over a 16-gauge catheter to maintain a minimal lumen for later balloon dilation. Venous blood flow from the SVC to the pulmonary vasculature is established while the venous return from the inferior vena cava enters the systemic atrium through the multifenestrated baffle (Fig. 1). Thus a bidirectional Glenn circulation is established. During the subsequent intervention, the holes in the baffle are occluded and the banded cardiac end of the SVC is reopened by balloon angioplasty.

Results. From April 1, 1994, to August 31, 1994, seven children having at least two risk factors for the Fontan operation (elevated pulmonary artery pressure, distortion of the pulmonary arteries, and regurgitant atrioventricular valves) between 2 and 13 years of age received a multifenestrated baffle and SVC banding. Mean bypass time was 97 minutes (86 to 128 minutes) and mean crossclamp time 31 minutes (19 to 79 minutes). Oxygen saturation after discontinuation of cardiopulmonary bypass was $76 \%$ 


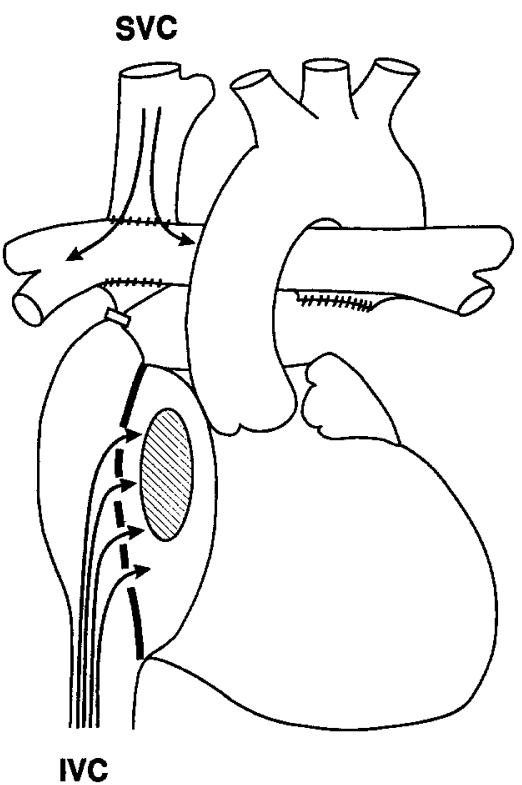

Fig. 1. Sketch of the operative procedure. Note the banding of the superior vena cava close to the cavopulmonary anastomosis and the multifenestrated baffe, which allows the inferior caval return to mix with the pulmonary venous return through an atrial septal defect. $S V C$, Superior vena cava; $I V C$, inferior vena cava.

( $70 \%$ to $81 \%$ ). Postoperative recovery of all patients was rapid, with extubation between 3.5 and 12.5 hours (mean 6 hours) after the operation and discharge to the ward the morning of the first postoperative day. No fluid retention or pericardial, pleural, or abdominal fluid effusions occurred. Total chest tube drainage was $16.3 \mathrm{ml} / \mathrm{kg}$ (11 to 22 $\mathrm{ml} / \mathrm{kg}$ ). Oxygen saturation at discharge, with the patients breathing room air, was $77 \%$ (75\% to $79 \%$ ). In all seven children, successful conversion to total cavopulmonary connection was performed with the interventional debanding of the SVC and closure of the fenestrations (Fig. 2). In the first three patients, the catheter intervention was performed with general anesthesia; in the subsequent four children, sedation was given only during the procedure. During the rather short follow-up, no complications occurred.

Comment. The Fontan principle is currently applied to a variety of clinical settings, and indications for the operation have been broadened through the installment of several modifications leading to a concept of staged operations. We describe an additional modification preserving the concept of the staged approach. During the operation, a bidirectional Glenn circulation is created and preparatory measures are performed that allow subsequent transcatheter completion to the Fontan circulation. These include creation of total cavopulmonary connection with banding of the cardiac end of the SVC to establish pulmonary perfusion through the cranial SVC, as in the setting of the bidirectional Glenn operation. Indeed, all
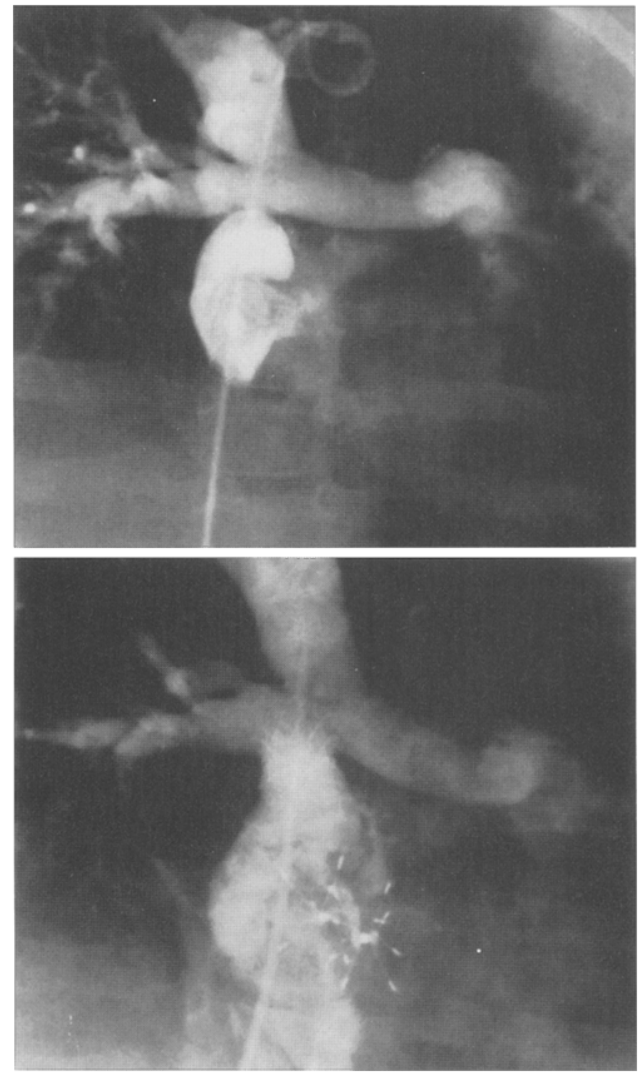

Fig. 2. Angiogram after completion of the Fontan circulation. The five holes of the lateral baffle have been closed with two Rashkind PDA occluders.

patients recovered from the operation uneventfully and none of the typical "Fontan complications" occurred. The postoperative course of the seven patients was as smooth as in patients with the bidirectional Glenn operation. The main goal of the staged approach, namely, unloading the heart by directing $30 \%$ to $50 \%$ of the systemic venous return to the pulmonary artery, is completely achieved. The ventricles are allowed to remodel and the catheter intervention for Fontan completion can be performed in due time. During the operation only a brief period of cardioplegic arrest is needed, which may be beneficial for rapid recovery, as well as for improved long-term function. Because only a small strip of the right atrium is exposed to high pressure, several long-term sequelae of the Fontan operation are erased, as with the lateral tunnel concept. ${ }^{1}$ As in the setting of the other recent modifications of the Fontan operation, however, long-term follow-up has to prove the value of this concept.

\section{REFERENCES}

1. Castaneda AR. From Glenn to Fontan: a continuing evolution. Circulation 1992;86(Suppl):II80-4. 
2. Bridges ND, Lock JE, Castaneda AR. Baffle fenestration with subsequent transcatheter closure. Circulation 1990;82:1681-9.

3. Bridges ND, Jonas RA, Mayer JE, Flanagan MF, Keane JF, Castaneda AR. Bidirectional cavopulmonary anastomosis as interim palliation for high-risk
Fontan candidates: early results. Circulation 1990; 82(Suppl):IV170-6.

4. Marcelletti C, Corno A, Giannico S, Marino B. Inferior vena cava-pulmonary artery extracardiac conduit: a new form of right heart bypass. J THORAC CARDIOvasc SURG 1990;100:228-32.

\section{RECONSTRUCTION OF THE PULMONARY ARTERY BY A CONDUIT OF AUTOLOGOUS PERICARDIUM}

Erino A. Rendina, MD, ${ }^{\mathrm{a}}$ Federico Venuta, MD, ${ }^{\mathrm{a}}$ Tiziano De Giacomo, MD, ${ }^{\mathrm{a}}$ Dario Carmine Vizza, MD, ${ }^{\mathrm{b}}$ and Costante Ricci, $\mathrm{MD},{ }^{\mathrm{a}}$ Rome, Italy

In patients with lung cancer, lobectomy associated with resection and reconstruction of the pulmonary artery (PA) has numerous advantages over pneumonectomy. ${ }^{1-3}$ Technically, after the infiltrated portion of the PA has been excised, the vessel can be reconstructed by end-toend anastomosis, ${ }^{4}$ by a pericardial patch, ${ }^{1}$ or by the interposition of a prosthetic conduit, ${ }^{5}$ according to the extent of the defect. For extended circumferential defects in which end-to-end anastomosis is not feasible, we have used a conduit of autologous pericardium. This technique, which has not been previously described, forms the subject of our report.

The technique was used in two patients with bronchogenic carcinoma of the upper lobe of the left lung with massive infiltration of the PA. The upper lobe bronchus was free from tumor infiltration, however, and therefore bronchial sleeve resection was not performed. This unusual situation (PA sleeve without bronchial sleeve) produced a long bronchial segment separating the two widely spaced PA stumps, so that an end-to-end anastomosis would not be possible.

We $\mathrm{e}^{1}$ have described in detail the preparation of the operative field for $\mathrm{PA}$ resection and reconstruction. After the surgical specimen has been removed and the feasibility of an end-to-end anastomosis excluded, a patch of pericardium of 3 by $3 \mathrm{~cm}$ is harvested. ${ }^{1}$ The pericardium is then trimmed to a rectangular shape, wrapped around a $28 \mathrm{~F}$ chest tube with the epicardial surface inside, and sutured longitudinally with 6-0 monofilament nonabsorb. able material. A pericardial conduit of approximately 1.5 to $2 \mathrm{~cm}$ is thus created. The conduit is then pulled out of the chest tube, laid in the operative field, and anastomosed to the proximal stump of the PA with running 5-0 monofilament sutures (Fig. 1). The distal anastomosis is performed last (Fig. 2), after the conduit has been trimmed to the appropriate length by overlapping the

From the Departments of Thoracic Surgery a and Cardio-Pulmonary Medicine, ${ }^{b}$ University of Rome "La Sapienza," Rome, Italy.

J Thorac Cardiovasc Surg 1995;110:867-8

Copyright @ 1995 by Mosby-Year Book, Inc.

$0022-5223 / 95 \$ 5.00+0 \quad \mathbf{1 2 / 5 4 / 6 3 9 9 0}$

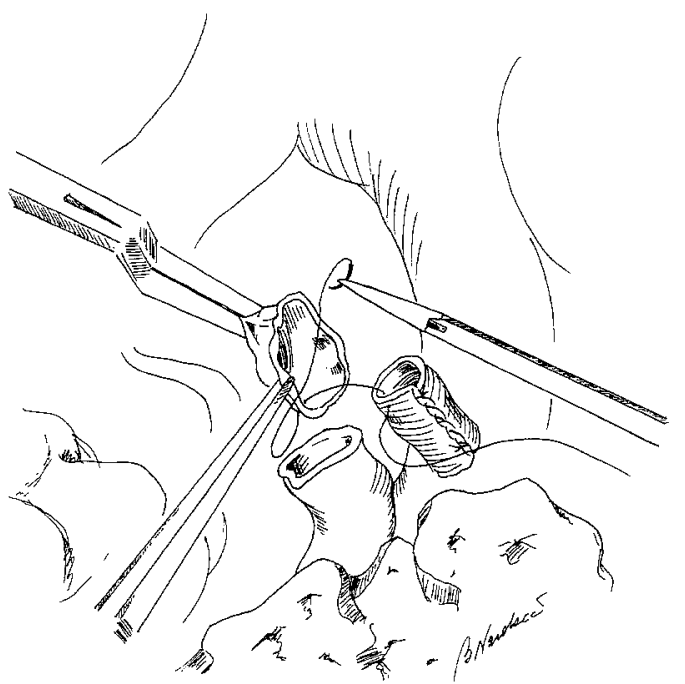

Fig. 1. The pericardial conduit is first anastomosed to the proximal stump of the PA.

suture margins. With tension, the dimensions of the conduit increase by $20 \%$ to $30 \%$. Therefore care must be taken to avoid excessive lengthening of the PA, because a long PA could result in kinking of the vessel, impaired blood flow, and ultimately thrombus formation. Anticoagulation is performed as reported elsewhere. ${ }^{1}$ Operative time was 3 hours in both cases.

Between March 1990 and August 1994 we performed 25 $P A$ reconstructions, and in two of these $(8 \%)$ we used the pericardial conduit. As $w^{1}$ previously reported, endto-end anastomosis or a pericardial patch is usually appropriate to reconstruct the PA. However, in some cases the tumor involves the PA so extensively that extended resection of the vessel is mandatory, and the PA stumps are not long enough for end-to-end anastomosis. A vascular segment therefore must be replaced. The use of spiralled saphenous grafts and polytetrafluoroethylene prostheses has recently been described. ${ }^{5}$ However, harvesting and tailoring the saphenous graft 